\title{
AS NOVAS TECNOLOGIAS E O USO DOS RECUR- SOS TELEMÁTICOS NA EDUCAÇÃO CIENTÍFICA: A SIMULAÇÃO COMPUTACIONAL NA EDUCAÇÃO EM FÍSICA
}

Antonio Jorge Sena dos Anjos

Universidade Estadual de Feira de Santana

Feira de Santana - BA

\section{Resumo}

Este estudo apresenta uma breve e panorâmica visão crítica sobre o uso das Tecnologias da Informação e Comunicação na Educação e, em especial, na Educação em Ciências, buscando, mais precisamente, centrar nossa atenção nos recursos da informática, com ênfase no uso e na adequação dos programas de simulação no ensino da Física.

Palavras-chave: Tecnologias da Informação e Comunicação; Educação em Ciências.

\begin{abstract}
This study presents a brief and panoramic critical view on the use of Information and Communication Technologies in Education, specifically in Science Education. The focus is centred in the resources of technology, emphasizing the use and adequate programs for Physics Teaching.
\end{abstract}

\footnotetext{
+ The new technologies and the use of telematics resources in Scientific Education: a computational simulation in Physics Teaching

* Recebido: novembro de 2007.

Aceito: julho de 2008.
} 
Keywords: Information and Communication Technologies;

Science Education.

\section{Introdução}

Admitindo o inegável avanço das tecnologias usadas para informação e comunicação entre as pessoas, este trabalho propõe que se traga para reflexão elementos que dão conta da utilização dessas tecnologias no âmbito da Educação formal. Em especial, o nosso foco de interesse são as tecnologias de informação e comunicação (TIC) que se utilizam, sobretudo dos recursos televisivos e informáticos.

Na verdade, desde as últimas décadas do século passado até o momento atual, os computadores cada vez mais têm "invadido"” as escolas, fato que requer dos agentes educacionais posicionamento crítico e consciente.

Não podemos mais continuar formando aquele ser humano mercadoria, mão de obra barata para uma sociedade tecnológica. Precisamos, e ai a escola pode ter um importante papel, formar um ser humano programador da produção, capaz de interagir com mecanismos maquínicos da comunicação, um ser humano participativo que saiba dialogar com os novos valores tecnológicos e não um ser humano receptor passivo (PRETTO, 2001, p. 220).

Tentando, portanto, refletir sobre as transformações dessa Escola, tendo em vista a formação do sujeito aprendiz e analisando as vantagens e desvantagens, os riscos e benefícios do uso dos computadores nos processos de ensino e aprendizagem, procuramos, ao longo desta obra, responder a algumas indagações, enfocando alguns tópicos que julgamos pertinentes para a composição deste trabalho.

Após algumas considerações iniciais sobre o uso das novas Tecnologias da Informação e Comunicação entre as pessoas, voltamo-nos mais especificamente para o uso da informática na Escola. Em "Informática Educativa ou Informática na Escola?", portanto, procuramos refletir justamente em torno dessa questãotítulo, trazendo, para tanto, elementos da literatura que dão suporte a essa discussão.

A seguir, em “Computadores em sala de aula: usos e limitações”, afunilamos nosso estudo sobre o uso e as limitações dos computadores nas práticas escolares como recursos didático-pedagógicos, bem como a posição do professor enquanto mediador do processo educacional. 
É evidente que, em um trabalho como este, não poderíamos deixar de destacar alguns dos expedientes mais disponibilizados pelos recursos telemáticos à educação, a exemplo de jogos, comunicações, ensino a distância, programas comerciais e educacionais, simulações, internet, entre outros, aos quais dedicamos breves comentários e reflexões.

Para finalizar, diante da vasta gama de recursos telemáticos, procuramos nos deter em apenas um deles: os programas de simulação. Esses softwares se constituíram na nossa principal área de interesse por serem bastante utilizados no contexto educacional, especialmente na educação em ciências e no ensino de Física, em particular.

\section{Novas tecnologias em educação}

Ao falarmos de informação e comunicação entre pessoas e entre povos, em geral, estamos falando de recursos utilizados por nós, humanos, como forma de estabelecer interrelações entre sujeitos. Isso vem ocorrendo desde a forma mais usual, porém atual, da oralidade e da escrita (primeiras tecnologias criadas pelo homem), seguidas de outras tecnologias, como o telégrafo, o rádio, o telefone, o videocassete, a TV e o computador, que se constituem em aparatos tecnológicos cada vez mais sofisticados, de transmissores de mensagens entre o sujeito-emissor e sujeito-receptor, ao longo dos tempos.

O século XX foi demarcado por extraordinários e relevantes estudos científicos. O desenvolvimento das ciências foi, e continua sendo, marcado por grandes descobertas e avanços tecnológicos que têm contribuído fortemente para significativas transformações nas relações entre tecnologia e sociedade. Nesse contexto, embora consideremos de grande relevância outros recursos tecnológicos já mencionados, destacaremos aparatos que geraram transformações ocorridas no final do século passado, mais especificamente as relacionadas com os sistemas de informação e comunicação, cuja expansão ocorre sem limites nos diversos setores da atividade humana, protagonizando trocas de informações e o surgimento de relações sociais que conectam entre si realidades reais e virtuais. Tudo isso,

[...] altera significativamente o meio e favorece o surgimento de relações antes não estabelecidas, que irão tecer uma complexa rede de possibilidades. $O$ endereço dessa complexa rede é nomeado de ciberespaço, que proporciona uma reconfiguração da noção de tempo, tornando-o instantâneo, e uma desmaterialização do espaço. No ciberespaço, as pessoas edificam interfaces imersas numa 
realidade, para se comunicar, relacionar e produzir saber, vindo a construir o chamado mundo virtual (COUTO; FONSECA, 2005, p. 55).

Compreende-se esse mundo virtual como uma ampliação dos padrões sociais já estabelecidos, onde pessoas no mundo cibernético buscam outras formas de se comunicarem, relacionarem e conhecerem sem, entretanto, se preocuparem com a formação de valores ao expressarem suas idéias, fantasias, seus desejos e saberes.

Nesse contexto de profundas e radicais transformações, onde e como se situa a Escola? Qual tem sido o seu papel? Como estão sendo (re)elaborados os currículos das escolas, tendo em vista essas novas demandas? E as práticas de ensino e aprendizagem na perspectiva do ciberespaço e da autoformação, como têm concorrido no ambiente escolar? E a formação docente, nos diversos ramos do saber, tem capacitado os egressos para atender a tais demandas?

Essas e outras indagações constituirão o objeto de reflexão ao longo deste texto, como forma de fundamentar e contextualizar o nosso trabalho.

Nós, professores, juntamente com as instituições de ensino, estamos sendo tomados por um discurso que profetiza o fim da instituição Escola, como conseqüência do surgimento das novas e avançadas tecnologias de informação e comunicação (TIC). Para aqueles que acreditam em tal fato, a era do estudante autônomo já começou. Porém, quando voltamos nosso olhar para dentro da Escola, verificamos nas práticas docentes que muito pouco daquilo que se propõe e/ou se pratica tem consistência pedagógica.

O uso dessas tecnologias no âmbito da Escola ou da Universidade ainda é muito incipiente sob a ótica de uma perspectiva construtivista. Como diz Jacquinot (citado por ALAVA, 2002, p.13), “[...] ainda é muito comum e freqüente 'fazer o velho com o novo"'. Nesse sentido,

[...] o ciberespaço não pode ser reduzido a um espaço tecnológico que permite assegurar melhor a transmissão passiva de saberes. A emergência de novos dispositivos de formação abertos na universidade, no campo da formação profissional, nos bancos das escolas ou no interior dos estabelecimentos escolares tende a colocar de novo na ordem do dia idéias antigas, mas sempre atuais, de trabalho colaborativo, de autonomia dos aprendizes e métodos ativos. Assim, o ciberespaço é concebido e estruturado de modo a ser, antes de tudo, um espaço social de comunicação e de trabalho em grupo. Portanto, o saber já não é mais o produto préconstruido e 'midiaticamente' difundido, mas o resultado de um 
trabalho de construção individual ou coletivo a partir de informações ou de situações midiaticamente concebidas para oferecer ao aluno ou ao estudante oportunidades de mediação (ALAVA, 2002, p.13 - 14).

Esse contexto de ocorrências suscita o estabelecimento de uma nova relação entre o professor e o aluno; uma relação não mais centrada no professor e no seu saber, como ocorre na pedagogia tradicional. Por outro lado, a simples existência dessas novas tecnologias num processo didático-pedagógico, não o torna mais rico, estimulante, desafiador e significativo para o aprendiz. Não saber adequar o uso pedagógico das novas tecnologias, significa permanecer tradicional usando novos e emergentes recursos.

Ainda hoje, é predominante a prática da abordagem tradicional, na qual o aluno, na condição de recipiente, serve de depósito para os saberes do professor. Sendo assim, os conhecimentos não são construídos; constituem-se em informações transmitidas pelo professor e decoradas pelo estudante. Para Freire, a construção de conhecimentos é muito mais do que uma simples transmissão, visto que:

no processo de aprendizagem, só aprende verdadeiramente aquele que se apropria do aprendido, transformando-o em apreendido, com o que pode, por isto mesmo, reinventá-lo; aquele que é capaz de aplicar o aprendido-apreendido a situações existenciais concretas. Pelo contrário, aquele que é 'enchido' por outro de conteúdos cuja inteligência não percebe; de conteúdos que contradizem a forma própria de estar em seu mundo, sem que seja desafiado, não aprende (FREIRE, 1979, p. 27-28).

Bianchetti e Ferreira (2005, p.154) acreditam que, nessa perspectiva, a interatividade entre professor e aluno é uma possibilidade de construção de conhecimentos significativos que poderão ocorrer coletivamente, interligando hipertextualmente diferentes conhecimentos.

Dessa maneira, cabe ao professor, enquanto mediador do processo de construção de conhecimentos, estimular e promover desafios junto aos educandos. Transmitir informações, ou coisa semelhante, já não deve ser mais papel do professor. Softwares, internet e outros recursos semelhantes podem muito bem realizar tal tarefa.

Para Lévy (apud Bianchetti e Ferreira),

[...] as TIC criam um processo de 'desintermediação', que signifi-

ca a eliminação de postos de trabalho em vários setores, uma vez 
que as pessoas passam a ser substituidas por tecnologias que realizam o trabalho que antes elas faziam. Na educação, contudo, por ser um trabalho eminentemente comunicativo, torna-se dificil pensar na eliminação completa do professor (Bianchettti; Ferreira, 2005, p. 154).

Podemos observar esse tipo de situação, por exemplo, nos cursos de Educação à Distância (EAD). Nessa experiência, tem-se constatado que se consegue um maior aproveitamento da aprendizagem e melhor rendimento dos estudantes quando os cursos são desenvolvidos também com etapas presenciais. Assim, o processo educativo depende da presença e da troca entre pessoas e, como tal, a participação do educador é indispensável, como articulador, comunicador e mediador na construção dos conhecimentos. Todavia, "o professor transmissor de conteúdos e antidialógico, muito provavelmente, estará próximo da desintermediação, pois as TIC oferecem informações mais atuais e com possibilidades interativas" (BIANCHETTI; FERREIRA, 2005, p. 154).

Diante de informações acessadas pelos alunos nas redes de comunicação, cabe ao professor, pedagogicamente, enriquecê-las, atribuindo-lhes significados, relacionando-as com outros conteúdos, com a cultura dos aprendizes e suas experiências de vida. Conforme Lévy (1993),

a operação elementar da atividade interpretativa é a associação; dar sentido a um texto é o mesmo que ligá-lo, conectá-lo a outros textos, e portanto é o mesmo que construir um hipertexto. É sabido que pessoas diferentes irão atribuir sentidos por vezes opostos a uma mensagem idêntica. Isto porque, se por um lado o texto é o mesmo para cada um, por outro o hipertexto pode diferir completamente. O que conta é a rede de relações pela qual a mensagem será capturada, a rede semiótica que o interpretante usará para captá-la (p. 72).

Falando em hipertexto, enquanto mundos de significação, o próprio Lévy (1993, p. 25-26) propõe caracterizá-lo através de seis princípios, segundo ele, abstratos:

1. Princípio da metamorfose

A rede hipertextual está em constante construção e renegociação. Ela pode permanecer estável durante um certo tempo, mas esta estabilidade é, em si mesma, fruto de um trabalho. Sua extensão, sua composição e seu desenho estão permanentemente em jogo para os atores envolvidos [...]. 


\section{Princípio de heterogeneidade}

Os nós e as conexões de uma rede hipertextual são heterogêneos. Na memória serão encontradas imagens, sons, palavras, diversas sensações, modelos, etc., e as conexões serão lógicas, afetivas, etc. [...].

3. Princípio de multiplicidade e de encaixe das escalas

O hipertexto se organiza em um todo 'factal', ou seja, qualquer nó ou conexão, quando analisado, pode revelar-se como sendo composto por toda uma rede, e assim por diante, indefinidamente, ao longo da escala dos graus de precisão. [...].

\section{Princípio da exterioridade}

A rede não possui unidade orgânica, nem motor interno. Seu crescimento e sua diminuição, sua composição e sua recomposição permanente dependem de um exterior indeterminado: adição de novos elementos, novas conexões com outras redes, excitação de elementos terminais (captadores), etc. [...].

5. Princípio de topologia

Nos hipertextos, tudo funciona por proximidade, por vizinhança. Neles, o curso dos acontecimentos é uma questão de topologia, de caminhos [...].

6. Princípio de modalidade dos centros

A rede não tem centro, ou melhor, possui permanentemente diversos centros que são como pontas luminosas perpetuamente móveis, saltando de um nó a outro, trazendo ao redor de si uma ramificação infinita de pequenas raízes, de rizomas, finas linhas brancas esboçando por um instante um mapa qualquer com detalhes delicados, e depois correndo para desenhar mais à frente outras paisagens do sentido.

O autor supracitado considera o hipertexto como uma multimídia de caráter interativo em condições de adequação aos processos educativos, visto que, segundo ele, "é bem conhecido o papel fundamental do envolvimento pessoal do aluno no processo de aprendizagem. Quanto mais ativamente uma pessoa participar da aquisição de um conhecimento, mais ela irá integrar-se e reter aquilo que aprender" ( p. 40).

Se, por um lado, o uso das TIC na educação pode se constituir em dispositivos que facilitam o trabalho do professor e da escola, por outro pode significar para o docente um grande desafio, pois requer dele novas competências para saber lidar com novas exigências, além de uma postura diferenciada daquela usada nas aulas tradicionais. Nesse sentido, 
Sentar-se no banco de uma sala de aula e tornar-se novamente um 'aluno' talvez seja uma situação não muito confortante para um professor que pensa já saber o suficiente para ensinar, e mudar a sua práxis, talvez, seja para ele uma mudança desnecessária. Ele já está tão acostumado com as suas estratégias de ensino que qualquer mudança, e principalmente uma mudança 'tecnológica', trará consigo novos desafios que deverão ser enfrentados e que muitas vezes são encarados como verdadeiros bichos de sete cabeças (NASCIMENTO, 2001, p. 55-56).

Nesse aspecto, é muito difícil para o professor que teve sua formação, suas vivências e experiências baseadas numa pedagogia tradicional, abandonar uma metodologia com a qual já está acostumado e que domina muito bem, para adentrar numa área onde quase tudo, ou tudo, é novidade para ele. Tomar consciência das necessidades de mudanças e inserção de novas tecnologias para elaboração de uma nova proposta pedagógica significa, para esse professor, uma ameaça que tem como reação natural a resistência. Diante dessa situação, o que propor? O que fazer? Podemos encontrar algumas alternativas de solução, nas palavras de Nascimento (2001), que sugere:

Num primeiro momento é necessário que haja uma conscientização do professor acerca das potencialidades existentes tanto no computador, quanto nele próprio. E o que se vê é justamente uma ênfase maior sobre a máquina e em seu poder, surgindo o medo e a insegurança como conseqüências desta possivel aproximação. Só que sozinha esta máquina tão poderosa não é inteligente nem criativa e só será se contar com a mente do homem, ou seja, do professor (p. 60).

Portanto, fica evidente a importância do professor e a sua convivência com a "máquina", visando fortalecer as relações entre ambos (professor e máquina), quando se pensa num processo de re-significação de propostas pedagógicas envolvendo o uso de novas TIC. Como afirma Nascimento (2001), "De nada adianta ter uma escola informatizada se não existirem professores capazes de entender o grande desafio de pensar e agir sobre uma nova lógica" (p. 60-61).

Porém, nesse contexto de evoluções sociais e tecnológicas, Escola e Professor precisam estar atentos às reais necessidades de adequação das novas TIC aos processos de ensino e aprendizagem. Escolas e Professores precisam ir além de simples treinamentos de habilidades operacionais com os instrumentos e progra- 
mas; é preciso elaborar projetos articulados com as tecnologias de informação e comunicação, o que requer do Professor e da Escola outra postura. Segundo Ferreira (2003), o professor:

precisa ser um agente mediador, articulador de idéias e informações para interagir com os elementos tecnológicos (TV, Vídeo, computador, máquina filmadora, scanner, etc.), de forma a proporcionar a construção de conhecimento. Para que isso ocorra, são necessários uma formação continuada e um movimento constante de reflexão na ação e sobre a ação (p. 241).

E a Escola precisa:

tornar-se um espaço de trabalho e de formação, o que exige que ela tenha uma gestão democrática e práticas curriculares interdisciplinares que proporcionem a implantação de redes de formação continuada em serviço, oportunizando ao professor a possibilidade de construir projetos coletivos, refletir sobre a sua prática pedagógica, buscando as soluções mais adequadas aos problemas surgidos ( p. 242).

Nessa perspectiva de formação em serviço, o professor é solicitado a ser mais que um simples elemento multiplicador junto a outros colegas ou mediador junto aos seus alunos. É necessário que ele, que é o professor, desenvolva a postura de pesquisador e que, conjuntamente com os estudantes, busque novas e adequadas formas de aprendizagem, com base na reflexão e construção coletiva, visando à formação de cidadãos críticos e conscientes do seu papel na sociedade.

Assim, conforme Ferreira (2003), formar esse cidadão preparado para as exigências da sociedade atual requer não só aquisição de aparatos tecnológicos, mas uma ação pedagógica sintonizada com essas exigências e que, nesse contexto, o professor possa, fazendo usos das novas tecnologias, desenvolver práticas pedagógicas não lineares, mas sim estruturadas de forma hipertextual.

Pensar na educação de forma hipertextual é pensar de forma interativa, onde a comunicação entre professor e aluno acontece bidirecionalmente e não apenas na transmissão de informações por meio de único emissor. Dessa forma, ao modificar a comunicação, o professor redimensiona a sala de aula, convidando o aluno a ser autor e co-autor das produções. Assim elas se tornam produções coletivas de professor e alunos (FERREIRA, 2003, p. 242). 
Nesse contexto, comenta ainda a autora, ter uma sala de aula na perspectiva do ciberespaço não significa simplesmente uma transposição de aulas presenciais. A escola precisa trabalhar no sentido de que o conhecimento seja "construído a partir de interações múltiplas, extrapolando as dicotomias ensinar/aprender, certo/errado, professor/aluno" ( p. 246).

Assim, é preciso reconhecermos que o uso das TIC na educação não deve se limitar apenas à implantação de salas de audio-visual e laboratórios de informática nas escolas; é preciso que essas tecnologias sejam utilizadas como ferramentas potencializadoras na construção de saberes.

\section{Informática educativa ou informática na escola?}

Falar do uso da informática na escola é o mesmo que falar da sua utilização como ferramenta enriquecedora de ações educativas dentro de uma visão construtivista?

Se analisarmos atentamente as práticas educativas no contexto das escolas em geral, podemos observar que diversas são as preocupações e posturas adotadas por elas no que tange ao uso da informática: escolas que têm alguns poucos computadores que sequer servem para, simplesmente, demonstrar alguma coisa para os alunos, a título ilustrativo; escolas que possuem modernos e equipados laboratórios de informática mas que não são utilizados, graças à ausência de professores capacitados para lidar com os equipamentos ou, quando existem esses profissionais para manuseá-los, o fazem com ênfase na máquina e nos seus recursos, não no processo educativo; escolas que dispõem de bons laboratórios e modernos equipamentos que são utilizados como instrumentos e recursos que engrandecem o processo educativo e contribuem para a construção de conhecimentos e apreensão de saberes na perspectiva de uma formação cidadã. Com certeza, estas escolas constituem a minoria.

Indubitavelmente, apenas a inserção de computadores nas salas de aula nada garante, em termos de ensino e aprendizagem, se aqueles que fazem a escola (alunos, professores, coordenadores) não souberem, adequadamente, explorar os recursos existentes nesses equipamentos. Portanto, o processo de implantação da "informática educativa", como ferramenta enriquecedora do processo educativo, requer reflexão crítica e análise acurada, como afirma Haydt (1997):

É preciso adotar um posicionamento crítico face a qualquer inovação tecnológica, o que inclui o computador. O primeiro passo para isso é desmistificá-lo. Para acabar com o mito do computa- 
dor, é preciso encará-lo como uma máquina semelhante a qualquer outra, criada e manipulada pelo homem e cuja influência sobre a sociedade requer uma análise crítica [...]. O emprego do computador no processo, assim como o uso de qualquer tecnologia, exige do educador uma reflexão crítica (HAYDT, apud COX, 2003, p. 33).

Partindo-se da premissa de que a Escola já dispõe de computadores, acessórios e softwares, o que fazer com essas inovações tecnológicas? Os computadores são equipamentos programáveis, por conseguinte podem ser utilizados para diversos fins tais como: máquina de escrever, base de dados, tutor de estudos, meio de comunicação entre pessoas, além de outros, não menos importantes, como auxiliar na gestão escolar.

Nesse sentido, cabe à escola buscar a melhor adequação desses equipamentos, programando-os para atender aos objetivos da educação formal. Para tanto, faz-se necessário, à escola e aos professores, conhecer métodos e processos relativos à atividade escolar para que o uso dessas máquinas seja otimizado no processo de educar.

Métodos, processos, projetos pedagógicos, embora aceitos e comprovados, nem sempre se manifestam igualmente para clientelas distintas, o que consideramos natural por se tratar de pessoas e com pessoas no contexto educacional. Se o contrário ocorresse, bastar-nos-ia programar os computadores para educar as pessoas. Conforme Valente (apud Cox, 2003, p. 20):

Os computadores estão propiciando uma verdadeira revolução no processo ensino-aprendizagem. Uma razão mais óbvia advém dos diferentes tipos de abordagens de ensino que podem ser realizados através do computador, devido aos inúmeros programas desenvolvidos para auxiliar o processo ensino-aprendizagem. Entretanto, a maior contribuição do computador como meio educacional advém do fato do seu uso ter provocado o questionamento dos métodos e processos de ensino utilizados.

Não temos dúvida de que questionar métodos e processos educacionais é também (re)pensar o papel da educação escolar na perspectiva de capacitar o indivíduo para a vida; para sobreviver, saber tomar decisões e saber aprender sempre. Nesse sentido, Demo (1998, p. 13) coloca:

Tomamos educação como o processo de formação da competência humanistica histórica. Entendemos por competência a condição de 
não apenas fazer, mas de saber fazer e sobretudo de refazer permanentemente nossa relação com a sociedade e a natureza, usando como instrumentação crucial o conhecimento inovador. Mais que fazer oportunidade, trata-se de fazer-se oportunidade.

Entendendo aí por "fazer-se oportunidade" o mesmo que colocar-se, como ser humano, na condição de eterno aprendiz, que questiona enquanto se questiona e se (re)constrói indefinidamente.

Assim sendo, é possivel concluir o quão necessário se faz que a educação escolar se efetue de forma dinâmica, envolvendo agentes livres para propor soluções - professores, alunos, corpo administrativo desprovido da casca escravizadora da passividade - e, seja permeada por procedimentos que tornem o descobrir uma atividade presente e constante no viver de todo indivíduo (COX, 2003, p. 22).

A Escola, portanto, deve oportunizar ao educando a possibilidade de "desenvolvimento de sua capacidade de criar, de descobrir e descobrir-se, de caminhar com seus próprios pés alicerçados nas mais sólidas bases racionais” (Ibid., p. 24).

\section{Computadores em sala de aula: usos e limitações}

Para Cox (2003, p. 35): "o número de formas de uso dos Computadores tem seu limite nas fronteiras da capacidade criadora do homem".

Assim sendo, as várias formas de uso dos computadores no contexto escolar estão diretamente atreladas ao potencial criativo do ser humano. Logo, essas maneiras de como os computadores podem ser usados podem ser tão amplas e vastas quanto restritas, em função da alta ou baixa criatividade humana.

Buscando refletir sobre os recursos computacionais usados no contexto da sala de aula nos processos de ensino e aprendizagem, selecionamos alguns na perspectiva de Cox (2003) tais como: a simulação, os jogos, a comunicação, o ensino a distância, os programas comerciais e os programas ou softwares, além da modelagem computacional e da Internet.

\section{IV.1 Simulação}

O universo empírico destaca os processos analógicos; o universo numérico destaca os processos digitais; a simulação é a veloz ope- 
rativa integração destes domínios, empírico e numérico, analógico e digital. [...]. Um enumerado digital ou é empírico ou é um resultado tautológico. Uma simulação, por sua vez, permite transcender o empírico e fornece subsídios para alternativas criativas (TENÓRIO, 2003, p. 177).

Assim, aliar os conhecimentos prévios do aprendiz a um ambiente de simulação é criar epistemologicamente um espaço de experimentação pois, enquanto a experimentação lida com manifestações reais, contato físico, ..., a simulação lida com a virtualidade, o programa subjacente, ..., a imaginação.

A imaginação é uma forma de simulação na qual antecipamos novas configurações decorrentes da dinâmica de relações dos fenômenos objetos de imaginação. A imaginação é elemento essencial da capacidade de aprender, e seu correlato técnico, a simulação, constitui-se em um poderoso instrumento de exteriorização material da inteligência, e pode exercer influência marcante sobre a qualidade de nossa imaginação e de nosso aprendizado, e certamente se tornará uma ferramenta poderosa de ensino, assim como já é uma ferramenta fantástica de produção de conhecimento (TENÓRIO, 2003, p. 178).

Nesse sentido, o aluno, ao interagir com o modelo de uma determinada realidade, pode, a partir de suas hipóteses, experimentar idéias, tirar conclusões, ..., aprender.

Todavia, simulações devem adequar-se aos objetivos que se pretende alcançar, além de não ter pretensões de substituir atividades reais, concretas. Os softwares ou programas, por mais sofisticados que sejam, possuem variáveis, quantitativamente limitadas quando comparadas com o fenômeno real.

Portanto, a respeito de simulação, pode-se afirmar que:

[...] trata-se de uma alternativa que pode ser motivadora, instigante, pertinente, para discussão de conteúdos científicos. Oferece-se aos alunos a oportunidade de serem agentes de sua própria aprendizagem, de tomarem uma decisão e assumi-la, de analisarem dados e modificarem suas conclusões, seguindo os passos do método cientifico, sem entretanto estarem presos a uma receita hierarquizada de acontecimentos predeterminados pelo professor, como acontece frequentemente quando usamos o laboratório. Acreditamos que dessa forma estaremos contribuindo para formar o 
raciocínio crítico do aluno, futuro cidadão participante das deci-

sões da sociedade (EIVAZIAN, apud COX, 2003, p. 37).

\section{2 Jogos}

São inúmeros os jogos oferecidos com o uso de recursos computacionais. Muitos deles são úteis ao processo educacional, outros não. Entretanto, sob o ponto de vista educacional, a contribuição do professor é imprescindível.

Os jogos, em geral, através da sua dinâmica e apresentação, mostram-se, atraentes aos indivíduos. Seja pelas cores, pelos sons, pelas animações e imagens, seja pelas curiosidades e pelos desafios que apresentam, eles se constituem em ferramentas atraentes por proporcionar ao aprendiz diversão e prazer aliados à possibilidade de aprendizagem. A respeito dos diversos tipos de jogos, Cox (2003) comenta:

Hoje dispomos de uma verdadeira infinidade de jogos implementados com o uso da informática: simulação de guerras interplanetárias, perigosas aventuras em busca de tesouros perdidos, disputa de destreza e técnica entre mestres de artes marciais, provas de automobilismo, viagens a países mágicos de terror ou de maravilhosas fantasias e outros ( p. 38).

Falando sobre os jogos, enquanto situações que envolvem os estudantes num clima de desafio e imaginação, Pessoa (2002) observa:

Todo jogo é constituído por um conjunto de regras que exigem um esforço de memorização e rapidez de raciocínio, para registrar mentalmente os erros cometidos e as estratégias adequadas, de maneira a empregá-las corretamente na situação e no momento oportunos ( p. 111).

Lévy (apud Pessoa, 2002) alerta "que os jogos, incluindo aí os vídeogames, estão em sintonia com as novas competências cognitivas necessárias para novas formas de trabalho" (p. 112), a exemplo de rapidez de raciocínio, manipulação de modelos, descoberta de regras através de exploração, entre outras.

\section{3 Comunicação}

Como meios de comunicação, os computadores assumem muitas funções. Para tanto, eles são interligados em redes, compartilhando recursos através de um 
sistema de comunicação. Em uma rede, os computadores podem estar unidos por cabos, linha telefônica ou satélites.

Dessa forma, da interligação das máquinas de processar surgem: listas de discussão, páginas da World Wide Web (www), salas de bate papo, boletins eletrônicos e outras ferramentas úteis à troca de experiência entre remotos pesquisadores, estudantes elou curiosos, contribuindo sobremaneira com a integração social dos seres humanos (Cox, 2003, p.40).

Mas o que são essas ferramentas? Para que servem? Como são usadas? Vejamos algumas considerações com base nas afirmações de Cox (2003, p. 40-41):

- Listas de discussão (também conhecidas como listas de correspondência): nelas, um computador (o principal), com um endereço eletrônico, recebe mensagens e envia cópias para todos os assinantes da lista. Logo, o que cada usuário de uma lista escreve é remetido ao computador principal, que redireciona para todos outros elementos da lista. Normalmente, em uma lista de discussão é trabalhada apenas uma temática, que é de interesse dos assinantes daquela lista.

- Páginas WWW: estas são as iniciais que identificam a "World Wide Web" (grande teia mundial), popularmente conhecida como "Web". Trata-se de um sistema de informações na Internet que utiliza uma interface designada Hipertexto, usando recursos multimídia. Nestas páginas, são encontradas informações que vão desde propagandas a artigos científicos.

- Salas de bate-papo: também chamadas de chatters, ou chats, são canais de comunicação existentes entre computadores em funcionamento através dos quais pessoas do mundo inteiro conversam entre si em tempo real.

- Boletins eletrônicos: nestes, as notícias, as mensagens e as comunicações em geral, são geradas numa central de informações (computador principal) e enviadas para os endereços eletrônicos dos usuários assinantes ou cadastrados naquela fonte geradora. Nesse caso, a comunicação é unilateral.

Como podemos sentir, no âmbito da comunicação, os computadores em rede constituem um poderoso e rico acervo de ferramentas muito úteis para o desenvolvimento das práticas escolares, porém requer do professor, como mediador do processo educacional, um bom conhecimento sobre a aplicabilidade dessas ferramentas.

Falando a respeito do uso e da exploração desses recursos pelo professor, Seabra (apud COX, 2003, p. 42) diz: 
A troca de idéias com outros educadores do país e do exterior, a pesquisa em bancos de dados, a assinatura de revistas eletrônicas e o compartilhamento de experiências dão um novo significado à atividade docente. A troca de experiências tem-se revelado um poderoso alavancador do interesse participativo, gerando um ambiente fomentador da contínua autoformação dos professores - que se tornam agentes multiplicadores junto aos demais.

Também Lucena (apud Cox, 2003, p. 43) é enfático quando afirma que essa exploração:

[...] permite uma forma de construção do conhecimento mais aberta e não diretamente dirigida e controlada, na medida em que novos ambientes de aprendizagem proporcionam campos para trabalhos cooperativos, criativos e inovadores. Isto também transforma uma sala de aula em uma "oficina de aprendizagem" [...].

\section{4 Ensino à distância}

Uma prática bastante utilizada, desde meados do século passado, inicialmente através do rádio e depois via televisão, a Educação à Distância (EAD), atualmente com os recursos da informática, está cada vez mais sofisticada, permitindo, dessa forma, otimizar a comunicação com segurança e precisão. Assim, o uso dos recursos computacionais favorece a interação entre as pessoas envolvidas no processo, em tempo real, o que é de relevância significativa para qualquer processo educacional.

A EAD nos dias de hoje, ante as exigências que a vida contemporânea nos impõe, torna-se não só viável (com o advento dos avanços tecnológicos) como necessária para todos aqueles que desejam continuar seus estudos e que não dispõem de tempo livre para fazê-lo de forma inteiramente presencial. O que se pretende com essa modalidade de ensino "é possibilitar que pessoas possam cursar seus estudos em centros de excelência sem precisar desvincular-se de suas ocupações particulares e/ou profissionais" (COX, 2003, p. 44), além obviamente das vantagens econômicas, comparadas aos cursos presenciais. Nesse sentido,

a Educação à Distância mediada pelas Tecnologias da Informação e Comunicação, nesse contexto, apresenta-se como uma alternativa atraente para atender à formação continuada do professor, tanto das grandes cidades quanto do interior, já que torna possivel 
alcançá-lo em suas localidades, na escola, em suas residências ou em qualquer lugar onde tenha acesso à Internet (REZENDE et al, 2003, p. 374).

Entretanto, os debates e as discussões acerca da Educação à Distância ainda persistem. Ainda existe muito a ser estudado, refletido e discutido a respeito das suas peculiaridades, aplicações e validades.

\section{5 Programas Comerciais}

São programas ou softwares, muitas vezes comercializados juntamente com o próprio computador. Trata-se de planilhas eletrônicas, editores de texto, bancos de dados, programas de apresentação, entre outros.

Embora sejam usados para fins educacionais, esses programas não foram elaborados com esse objetivo e sim para outros fins mais práticos em outras áreas da atividade humana. Evidentemente, o uso desses programas na educação requer do professor adequação e contextualização dos mesmos no sentido de melhor utilizá-los no processo de construção do conhecimento.

As citações a seguir dão uma idéia melhor e mais fundamentada da utilização de alguns tipos desses programas no processo educacional.

Sobre a planilha eletrônica, Seak (1997) afirma que:

Com a planilha, o aluno, livre dos cálculos repetitivos e do trabalho cansativo e maçante da construção de tabelas, terá na tarefa de construir gráficos uma motivação para a pesquisa, a observação, a tirada de conclusões. E depois poderá, junto com o professor, formalizar suas descobertas (Seak, apud Cox, 2003, p. 46).

Falando a respeito do banco de dados, Albuquerque (1995) coloca:

Uma proposta da estruturação de um banco de dados a ser realizada pelos alunos servirá como um mecanismo bastante eficiente para se discutir com eles o que é planejar um trabalho intelectual: o porque de se escolherem tais ou quais objetivos, como pesquisar dados e informações e a importância de um trabalho coletivo numa empreitada como esta. (ALBUQUERQUE, apud COX, 2003, p. 47).

Comentando a respeito do processador de texto, Callazzo (1995) diz que: 
[...] com um computador e um datashow em sala de aula é perfeitamente possivel desenvolver atividades de linguagem a partir dos textos manuscritos dos alunos [...]. Com o auxílio do computador e do datashow [...] o professor poderá projetar o texto de um aluno, por exemplo, e discutir com a classe a linguagem por ele utilizada em sua produção, fazendo as adequações necessárias de acordo com o propósito do texto. Isto implica um trabalho de reflexão coletiva, em que o professor será o mediador deste e o manipulador das modificações necessárias do texto, através dos recursos do processador que permitem rapidamente tais alterações (CALLAZZO, apud COX, 2003, p. 47-48).

\section{6 Programa Educacional}

Como o próprio nome já diz, trata-se de programas ou softwares pensados e elaborados para atividades a serem desenvolvidas na educação escolar, em sala de aula, na forma de histórias interativas, enciclopédias, dicionários, tutorais, programas de exercício e prática, autoria, linguagem Logo, entre outros, a exemplo do já citado software de simulação.

Vejamos, em brevíssimos comentários sobre cada um desses tipos de programas educacionais, quais as suas características e sua aplicabilidade nos processos de ensino e aprendizagem com base na opinião de Cox (2003, p. 48-51):

- Histórias educativas: oferecem possibilidades aos indivíduos de ruptura de posturas passivas nas atividades escolares e possivelmente na vida, visto que a tradicional linearidade dos contos infanto-juvenis é quebrada, favorecendo a interação do leitor com os personagens, as cenas e as ações.

- Enciclopédias e dicionários: são dispositivos onde os alunos podem encontrar, além de uma vasta base de dados textuais, animações, imagens, gráficos, cores e movimentos que podem contribuir para trabalhos de pesquisa mais dinâmicos e prazerosos. Contando ainda com as estratégias de buscas, como consulta por palavras-chave ou seqüencial, ou ainda através de hipertextos ou links, os estudantes podem coletar dados, complementar conteúdos estudados nas aulas, elaborar hipóteses; enfim, informar-se e construir bases para sua formação.

Uma observação se faz necessária: existem pesquisadores que consideram os trabalhos com enciclopédias e dicionários como tradicionais, retrógrados e não formativos.

- Tutoriais/exercícios e prática: os programas tutoriais são expedientes que apresentam informações ou seqüência de conteúdos e questionamentos varia- 
dos, exigindo respostas freqüentes dos alunos. Já os programas de exercício e prática são uma espécie de estudo dirigido, interagem com o estudante propondo questionamentos, analisando as respostas e apresentando o resultado da "avaliação" em termos de acertos e erros. Muito usados no passado, atualmente muitos pesquisadores condenam o uso desses programas, considerando que os mesmos não contribuem para o processo de formação de competências do educando pois, segundo eles, esses programas apenas informam.

- Linguagem Logo: Esse programa foi criado por Seymour Pappert, professor de matemática e educação do Instituto de Tecnologia da Massachussetts (MIT) e autor de várias obras sobre educação, dentre as quais, Logo: computadores e educação, na qual, fazendo uso do Logo, apresenta um sistema de ensino de conceitos fundamentais de matemática e da ciência em geral para crianças.

A linguagem Logo pode ser entendida como um ambiente baseado nos princípios construtivistas de Piaget e voltado para o desenvolvimento do raciocínio lógico e para a capacidade de pensar do aprendiz.

Muito embora possua uma boa fundamentação nos princípios supracitados, o seu uso, sem critérios de estudo e planejamento dos pretensos objetivos educacionais a serem atingidos, pode ser comprometido.

- Programas de autoria: também denominados softwares abertos, esses programas possibilitam o desenvolvimento de aplicações de multimídia (pequenos programas compostos por textos, animações, sons, hipertextos, vídeos, gráficos...) sem o necessário uso direto de linguagens de programação. Com esse tipo de software, os envolvidos no processo educacional podem desenvolver muitos dos modelos aqui citados (tutoriais, exercício e prática, jogos, simulações ...) para tratar a temática estudada.

Para concluir essa reflexão em torno dos programas a serviço da educação escolar, cuja eficiência, como vimos, está na forma de uso e não apenas na sua simples utilização, citamos Cox (2003) que afirma:

É preciso observar que não é suficiente, para garantir a eficiência de software, que ele seja desenvolvido nos designios dos postulados de uma teoria educacional. A aplicação da informática na educação, mesmo recorrendo a programas desenvolvidos especificamente para o ambiente educacional escolar, sempre exige dos agentes escolares postura crítica e capacitação contínua ( p. 52).

Assim sendo, “[...] na Escola, aluno e professor, errantes em busca de um caminho, resgatam, não a beleza da máquina, mas a beleza de aprender, na institui- 
ção, o lado humano da qualidade através do pensamento" (BUSTAMANTE, apud PESSOA, 2002, p. 117).

Os programas que fazem uso de diferentes tipos de mídias podem criar os chamados ambientes multimídia de aprendizagem, os quais permitem implementar uma rede de informações ligadas entre si, na qual várias mídias podem ser exploradas simultaneamente pelos educandos utilizando recursos (gráficos, textos, vídeo...) apropriados para o desenvolvimento de experiências interativas e cooperativas (PESSOA, 2002, p. 117).

O uso do computador na educação também se faz com a existência de uma outra modalidade advinda das chamadas redes telemáticas (associação resultante dos recursos da informática e das telecomunicações) que se viabilizam por meio de conexões Físicas entre as máquinas de processamento (computadores) ou através de uma interface ou modem, que faz a conexão entre o computador e a rede de telefone. Essa tecnologia, ou combinação de tecnologias, potencializa o computador como um significativo e excelente meio de comunicação.

A rede telemática mais conhecida e largamente usada em todo mundo é a rede mundial de computadores, a Internet. Sobre essa rede telemática, Cianconi (1999) comenta:

A comunicação na Internet tem características próprias. Os usuários são membros de uma comunidade virtual e protegem a qualidade dessa comunicação. A informação é o grande produto. $O$ marketing está mudando para atender a essa nova demanda por informação útil. É um novo paradigma que se estabelece, em que a interatividade, a resposta imediata, a relação entre as partes são $o$ marco (CIANCONI, apud PESSOA, 2002, p. 120).

Também é preciso ficar atento para problemas que surgem em decorrência do uso da telemática na educação.

A Internet, apesar da disponibilidade de grande e variada quantidade de informações, requer muito cuidado quanto ao seu uso. Marchand (2002), baseado em Morin (2000), é enfático quando diz: "Na informação, os dados estão organizados dentro de uma determinada lógica, de um código, de uma estrutura. Conhecer é integrar a informação ao nosso referencial, tornando-a significativa para nós" (p. 121).

Por isso, segundo Pessoa (2002), ao utilizarmos novas TIC na educação, é de importância fundamental a definição de uma metodologia que possibilite a integração entre informação e conhecimento a partir da interação entre aluno, professor e computador num ambiente viabilizador de aprendizagem (p.121). 
É imprescindível, portanto, a definição de uma metodologia na qual a intervenção do professor, enquanto mediador do processo educacional, deva ser a de estimular o aprendiz a tomar consciência de suas dúvidas e certezas, como também ajudá-lo a articular as novas informações com os seus conhecimentos prévios, na busca por uma aprendizagem significativa.

Como se pode observar pelo exposto, é muito vasto o espectro de possibilidades da utilização das tecnologias de informação e comunicação, em especial informática e telemática, no campo da educação escolar.

Muitos desses inúmeros recursos foram brevemente comentados ao longo da nossa exposição. Justamente por serem muitos os expedientes oportunizados pela computação, aqui neste texto, elegemos um e apenas um recurso da informática para ser melhor e mais profundamente explorado. Esse recurso são os programas ou softwares de simulação que, em particular, são bastante utilizados na educação em ciências e, especialmente, no ensino de Física.

\section{Simulação computacional na educação em Física}

A Física, como ensinada nas salas de aula, carrega um alto grau de abstração no entendimento de vários conceitos e definições, além de lidar com materiais e objetos que estão fora do contexto de apropriação do ser humano.

Nesse sentido, os recursos didáticos disponibilizados aos alunos e professores no processo educacional em Física, têm evoluído visando atender às demandas e exigências que o ensino de tal disciplina requer. Nos livros didáticos, por exemplo, é visível a preocupação com o excesso de gravuras e ilustrações. Os professores, por sua vez, esforçam-se para esboçarem desenhos em suas aulas. Todas essas tentativas e esses gestos de ilustrações estáticos não dão conta de atender às reais necessidades do mundo complexo e dinâmico com que essa área do conhecimento (a Física) se ocupa.

Nessa perspectiva, parece-nos que os recursos computacionais constituem uma boa alternativa de solução para os problemas que o ensino de Física enfrenta. $\mathrm{O}$ uso de animações, simulações e possibilidades de outros recursos oferecidos pelos computadores podem contribuir substancialmente para facilitar o ensino e a aprendizagem em Física, podendo, em alguns casos, suprir, ainda que parcialmente, a ausência de equipamentos para experimentos.

A computação oferece a alternativa que através de simulações de experimentos permita melhorar em parte esta situação. Construir um experimento em um computador é mais barato, não se corre o 
risco de destruição do equipamento e pode repetir-se o experimento as vezes que sejam necessárias (CÓRDARA et al, 1992, p. 147).

No caso das simulações computacionais, estas são muito mais que simples animações, pois envolvem muitos recursos telemáticos, além de oportunizar a interatividade do aprendiz com a máquina.

A interatividade relaciona-se com o fato de que o programa é "capaz de fornecer [...] uma vasta gama de animações alternativas selecionadas através do input de parâmetros pelos estudantes" (MEDEIROS; MEDEIROS, 2002, p. 79).

Desta forma, por exemplo, para ilustrar o movimento de um projétil, uma simulação computacional permite ao estudante a escolha de parâmetros relevantes tais como a velocidade inicial e o ângulo de tiro, para os quais o programa fornece as respectivas animações geradas a partir de grandes bancos de dados (MEDEIROS; MEDEIROS, 2002, p. 79).

Baseado nas palavras destes autores, qualquer simulação tem por base um modelo de situação real, matematizado e processado pela máquina com fins de fornecer e de animar uma realidade virtual. É o modelo que dá suporte à simulação e lhe outorga significado.

Mas o que vem a ser um modelo? E a modelagem? Esses conceitos têm a ver com simulação? Antes de continuarmos a discorrer sobre o que nos propomos nesta seção, parece-nos conveniente e esclarecedor buscar ver na literatura especializada o que se fala sobre esses conceitos.

Para Tenório (2003):

[...] um modelo é instrumento eminentemente didático, pois trata de um fenômeno complexo de forma mais simples; além de didático, é lúdico, pois, especialmente quando se trata de simulações, pode-se brincar ou jogar com o modelo; de qualquer sorte, a manipulação do real fictício, cativa e dá prazer; tendo um modelo caracteristicas didáticas e lúdicas, pode desempenhar um papel importante para a construção do significado na atividade de ensino (p. 174).

Comentando sobre o conceito de modelagem, Pessoa (2002) coloca que "a modelagem nada mais é do que uma simulação desenvolvida pelo próprio aluno 
para representar um determinado fenômeno e testar suas hipóteses” (p. 112). E, baseada em Almeida (1997), essa autora diz:

As simulações e modelagens podem fornecer ao pensamento uma ferramenta auxiliar do raciocínio para a representação formal do real, que permite tornar presente um fato ou fenômeno inacessivel, propiciando sua evocação, manipulação, internalização, apropriação e transformação em conhecimentos (PESSOA, 2002, p. 112 113).

Tentando responder a uma das perguntas (o que vem a ser um modelo?) por nós formulada nesse texto, Veit e Araújo (2005) comentam:

Esta pergunta não tem uma resposta fácil. Teremos tantas definições quantas forem as perspectivas daqueles que as busquem. Entretanto, de modo geral, podemos definir um modelo como um análogo estrutural do sistema que ele representa, contendo elementos e relações fundamentais que reproduzem as características deste sistema dentro de um contexto de validade limitado, e sem a pretensão de ser uma imagem especular do mesmo ( p. 17).

Quanto à outra pergunta (E modelagem?) os autores respondem:

Em relação à modelagem, podemos defini-la como o processo de construção e análise de modelos, interessando-nos particularmente aqui na modelagem computacional aplicada ao ensino, ou seja, na elaboração e no estudo de modelos que, pelo menos em princípio, possam ser implementados no computador e tenham fins pedagógicos (VEIT; ARAÚJO, 2005, p. 18).

Referindo-se à modelagem computacional no ensino de Física, Veit e Araújo (2004) dizem:

A modelagem computacional aplicada a problemas de Física transfere para os computadores a tarefa de realizar os cálculos numéricos elou algébricos - deixando o físico ou estudante de Fisica com maior tempo para pensar nas hipóteses assumidas, na interpretação das soluções, expansões do modelo que possam ser realizadas (p. 58). 
Feitas essas considerações, voltemos ao foco desta seção, que é simulação por computador na educação que, como vimos, tem estrita relação com o modelo e a modelagem, até porque, como afirmam Medeiros e Medeiros (2002):

as simulações podem ser vistas como representações ou modelagens de objetos específicos reais ou imaginados, de sistemas ou fenômenos. Elas podem ser bastante úteis, particularmente quando a experiência original for impossivel de ser reproduzida pelos estudantes (p. 79).

$\mathrm{Na}$ Física em particular, as simulações têm sido alvo de grandes avanço e crescimento, visto que são inúmeras as produções de programas e é grande o interesse de pesquisadores por "desenvolverem simulações de fenômenos físicos, na esperança de que seus estudantes possam trabalhar sobre problemas seguindo os seus próprios ritmos individuais" (MEDEIROS; MEDEIROS, 2002, p. 79).

No entanto, mesmo contando com grande crescimento e utilização, as simulações ainda continuam sendo motivo de constantes e acirradas discussões no que se refere às vantagens, desvantagens e aos fundamentos e objetivos.

Falando-se em vantagens para o uso das simulações no ensino de ciências, Medeiros e Medeiros (2002, p. 80) referem-se ao trabalho de doutorado de Gaddis (2000), que faz um vasto levantamento das principais justificativas quanto a essa utilização. O citado pesquisador destaca, entre outros, os seguintes benefícios supostamente oriundos das simulações computacionais no ensino de ciências:

- Reduzir o 'ruído' cognitivo de modo que os estudantes possam concentrar-se nos conceitos envolvidos nos experimentos;

- fornecer um feedback para aperfeiçoar a compreensão dos conceitos;

- permitir aos estudantes coletarem uma grande quantidade de dados rapidamente;

- permitir aos estudantes gerarem e testarem hipóteses;

- engajar os estudantes em tarefas com alto nível de interatividade;

- envolver os estudantes em atividades que explicitem a natureza da pesquisa científica;

- apresentar uma versão simplificada da realidade pela destilação de conceitos abstratos em seus mais importantes elementos;

- tornar conceitos abstratos mais concretos;

- reduzir a ambigüidade e ajudar a identificar relacionamentos de causas e efeitos em sistemas complexos;

- servir como uma preparação inicial para ajudar na compreensão do papel de um laboratório; 
- desenvolver habilidades do raciocínio crítico;

- fomentar uma compreensão mais profunda dos fenômenos físicos;

- auxiliar os estudantes a aprenderem sobre o mundo natural, vendo e interagindo com os modelos científicos subjacentes que não poderiam ser inferidos através da observação direta;

- acentuar a formação dos conceitos e promover a mudança conceitual.

Como acabamos de ver, esses benefícios apontados constituem-se num quadro otimista e bastante favorável às possibilidades de uso das simulações no ensino das ciências naturais, muito embora existam limitações. Nesse sentido,

Cumpre-se analisar não apenas as alegadas vantagens educacionais; mas, igualmente, as bases epistemológicas das simulações computacionais que dão sustento aos prodigiosos beneficios que elas poderiam trazer para o ensino, no dizer de seus mais ardorosos defensores (MEDEIROS; MEDEIROS, 2002, p. 80).

Diante desse quadro de possibilidades, benefícios, mas também de limitações, existem aqueles que ainda não fazem uso das simulações, ou sequer de qualquer recurso informático no ensino das ciências. Sem descartar as limitações inerentes às simulações, arriscamos dizer que, possivelmente, uma grande limitação pode estar no próprio mediador do processo educacional, o professor. A este, é imprescindível, sensibilidade, conhecimento técnico, fundamentação crítica, competências e habilidades no trato com esses recursos, na busca de uma prática pedagógica que possibilite um ensino de Ciências prazeroso e significativo para o estudante.

Outras limitações, decorrentes do uso das simulações como recurso educacional no ensino da Física, estão relacionadas com a própria concepção do modelo que lhe dá suporte, como alerta Vedelsby (1996), citado por Medeiros e Medeiros (2002):

[...] os modelos, as simplificações e as idealizações constituem partes muito importantes bem como ferramentas fundamentais em nossa descrição do complexo mundo físico em que vivemos. Um bom modelo em Física é simples e capaz de fazer boas predições. Ele descreve e explica as partes principais dos fenômenos com os quais está relacionado e para os quais foi desenvolvido [...]. Desta forma, uma parte crucial da aprendizagem em Física é fazer com que os nossos estudantes compreendam e apreciem o conceito de 
um modelo, o que eles significam, para que foram construídos, seus pressupostos simplificadores e seus limitados contextos de validade (p. 82).

Assim, para estes autores, é preciso estar muito atento quanto à modelagem a ser usada na elaboração de um programa de simulação. Na construção dos modelos, devem ser criticamente levadas em consideração as características do sistema modelado, aquelas que devem ou não ser incluídas no modelo proposto.

Uma simulação usada no contexto da educação em Física deve representar para o estudante algo que venha contribuir para a construção dos conceitos de Física, para o entendimento dos fenômenos estudados e a apreensão da realidade Física. Uma simulação deve, portanto, nesse contexto, ir além de um simples papel ilustrativo, sob pena de não estimular, não proporcionar desafios, não estimular a curiosidade, ou sequer fazer o aprendiz pensar sobre a realidade simulada.

Por se apresentarem como sinônimo de evolução, progresso, atualidade, e se mostrarem atraentes, envolventes, "mágicos", os recursos de informática têm sido usados de forma indiscriminada no contexto educacional. Por muitas vezes, as simulações são usadas em atividades, desnecessariamente, sem a menor sensatez. Não é para o estudo de qualquer tipo de atividade, conceito ou fenômeno físico que cabe uma simulação.

É preciso ter-se em mente que o ponto de partida de toda simulação é a imitação de aspectos específicos de realidade, isto significando que, por mais atraente que uma simulação possa parecer, ela estará sempre seguindo um modelo matemático desenvolvido para descrever a natureza, e este modelo poderá ser uma boa imitação ou, por outras vezes, um autêntico absurdo. Uma simulação pode tão somente imitar determinados aspectos da realidade, mas nunca a sua total complexidade. Uma simulação, por isso, nunca pode provar coisa alguma. O experimento real será sempre o último juiz (MEDEIROS; MEDEIROS, 2002, p. 83).

Os autores acima citados colocam como exemplo de complexidade, as modelagens de sistemas atômicos, que extrapolam a memória finita, ainda que gigantesca, do computador. Todavia, por outro lado, consideram que:

a complexidade de uma simulação pode convenientemente ser adequada às necessidades reais dos estudantes e da situação de aprendizagem pretendida. Na impossibilidade da comparação com 
o real, a discussão da construção do modelo torna-se ainda mais importante e essencial ( p. 83).

Justamente por se constituir um recurso complexo, a simulação torna-se alvo de polêmica e divisão de idéias entre educadores e pesquisadores, estudiosos críticos, otimistas e mais severos. Nesse sentido, Medeiros e Medeiros (2002, p. 83), elencam alguns comentários baseados em diferentes autores, acerca dessa problemática.

Com relação ao posicionamento dos críticos mais severos da utilização, os autores destacam: "[...] as simulações computacionais parecem limitar a possibilidade de os estudantes serem confrontados com a riqueza heurística da experiência dos erros experimentais e, assim, da tentativa de resolverem problemas da vida real" (KIMBROUGH, 2000). "[...] os resultados nas simulações tendem a ser predeterminados, em lugar de estarem abertos à pesquisa mais especulativa e aos raciocínios mais abertos" (PROSSER; TAMIR, 1990). "A idéia central seria, portanto, pensar com a mente e calcular com o computador" (TRAMPUS; VALENJE, 1996).

Conforme Medeiros e Medeiros (2002), os críticos mais otimistas com as possibilidades da informática na educação e, em especial, com o uso das simulações por computador, apontam "que um problema geral no ensino da Física tem sido o uso precoce de símbolos e métodos matemáticos que atuam como uma barreira de entrada para muitos estudantes, conduzindo-os a uma experiência de insucessos e resignação" (p. 83).

É evidente que as simulações computacionais apresentam o mesmo nível de exatidão das matematizações, todavia os gráficos animados se constituem numa linguagem que parece comunicar mais diretamente, tornando-se mais acessível aos aprendizes. Assim, as soluções apresentadas por essa linguagem podem ser intermediárias na busca pela abstração, porém, apenas, intermediárias (MEDEIROS; MEDEIROS, 2002, p. 83)

Baseados em Snir (1998) e Sassi (1996), Medeiros e Medeiros (2002) colocam que "defensores mais otimistas do uso das simulações na educação têm creditado a elas um potencial de atuarem decisivamente na mudança conceitual". Eles chamam a atenção para que "nem a realização de experimentos reais pode garantir qualquer mudança conceitual, tal a riqueza das interpretações possíveis de variados aspectos da realidade" (p. 84). Comentam ainda que:

No caso do uso de simulações, as restriçães são ainda maiores, pois elas estão baseadas, como já apontado, em modelos que contêm necessários pressupostos que simplificam a realidade e o fun- 
cionamento do software é proporcionado por um banco de dados que pode ser grande; mas que, apesar disso, é limitado e não infinito.

Estudos realizados por Yeo et al (1998), citados por Medeiros e Medeiros (2002), sobre o potencial do computador em personalizar o ensino da Física, observando o comportamento de estudantes diante de uma simulação com movimento de projéteis, revelam que, quando deixados a sós interagindo com o software, suas interações com o conteúdo eram tímidas e limitadas (p. 84).

Quando os pesquisadores pediram aos estudantes para explicarem as suas observações, dois pontos ficaram evidentes: eles mantinham as suas concepções alternativas sobre o movimento dos projéteis e apenas seguindo as sugestões dos pesquisadores notaram e tentaram interpretar aspectos mais abstratos do programa (MEDEIROS; MEDEIROS, 2002, p. 84).

Isso reforça a necessidade da presença e intervenção do professor na condição de desafiador e mediador de um processo de engajamento cognitivo na busca pelo entendimento e pela apreensão da realidade Física.

Também Benito e Fern (1996), citados por Medeiros e Medeiros (2002), pesquisando sobre professores e alunos ao lidarem com simulações no ensino de Física, concluíram que "apenas professores podem explicar idéias e transmitirem certas visões da realidade Física, criticamente".

Segundo Medeiros e Medeiros (2002), para que haja aprendizagem e não apenas memorização, deve-se oportunizar ao aprendiz atividades com as quais ele se envolva cognitivamente. Sobre esse aspecto, Araújo e Veit (2005), com base na Teoria da Carga Cognitiva, são enfáticos quando dizem:

Para que o conhecimento seja armazenado na memória de longo prazo, é necessário que estímulos vindos do ambiente sejam processados pela memória de curto prazo, também dita memória de trabalho. Esta memória, entretanto, tem capacidade e duração limitada. $O$ respeito a estes limites, no desenvolvimento de material educacional, pode ser determinante no seu sucesso como facilitador da aprendizagem (ARAÚJO; VEIT, 2002, p. 47).

$\mathrm{Na}$ opinião de Medeiros e Medeiros (2002), o conhecimento precisa ser construído e reconstruído quando se pretende um efeito duradouro e não simplesmente transferido ou implementado. Até porque, o que se pode transferir são in- 
formações sobre o conhecimento. Isso requer uma "aprendizagem na interação com seres humanos, com o professor real". E, com base em Funke (1998), colocam que simulações podem ser ricas em imagens e em cálculos; mas são pobres em dimensão social.

\section{Considerações finais}

Do exposto, fruto das considerações trazidas para análises, discussões e reflexões, podemos concluir que as novas Tecnologias da Informação e Comunicação são presenças indispensáveis no contexto da educação. No entanto, também é possível inferir que, para uso de tais tecnologias, é preciso definir critérios, buscar competência técnica e possuir visão crítica no sentido de adequar as concepções de ensino e de aprendizagem às inovações tecnológicas.

Portanto, a simples presença das TIC no processo educacional não garante, apesar da inovação, um ensino de qualidade para o educador e uma aprendizagem significativa para o educando, visto que "o papel do educador não é o de 'encher' o educando de 'conhecimento', de ordem técnica ou não, mas sim o de proporcionar, através da relação dialógica educador-educando, educandoeducador, a organização de um pensamento correto em ambos" (FREIRE, 1979, p. $53)$.

Nesse sentido, as novas TIC, embora facilitem a comunicação e favoreçam a transmissão de informações em volume e velocidade, por si só não asseguram essa relação dialógica (educador/educando) visando à construção de conhecimentos. Sendo assim, e concordando com Ferreira e Bianchetti (2005):

acreditamos que, para desenvolver uma educação com a utilização das TIC, seja ela presencial, semi-presencial ou a distância, será importante um grande esforço dos profissionais da educação no sentido de concretizar a construção de ambientes de aprendizagem alternativos, onde os sujeitos envolvidos nesse processo tenham a possibilidade de criar, recriar, modificar, agir em tempo real, ser autores e co-autores de produções (p. 162).

Dessa forma, no processo de aprendizagem, a construção individual ou coletiva requer do professor muito mais do que conhecimentos teóricos e tecnológicos, ou mesmo o retórico dom de disseminar informações. Requer do professor que ele "esteja aberto para o mais comunicacional, para deixar o aluno expor suas idéias e trilhar seus próprios caminhos". 
Compete ao professor desafiar o seu aluno a entrar no labirinto, mergulhar no mundo de informações, relacionar saberes e buscar soluções para os problemas, e assim construir seus conhecimentos (FERREIRA; BIANCHETTI, 2005, p. 161).

Nesse contexto de uso das novas TIC na educação, e em especial no ensino da Física, chamamos a atenção para os programas de simulação, objeto de destaque e aprofundamento neste nosso trabalho.

Fica evidente que, em se tratando de um recurso computacional como esse, precisamos, como professores e mediadores do processo educacional, estar atentos para as vantagens, dificuldades e possibilidades que esses softwares podem nos proporcionar.

Portanto,

é indispensável explorar ao máximo as possibilidades de predizer o que ocorrerá à medida que introduzimos trocas nas grandezas do sistema fisico e explicar em termos dos conceitos fisicos envolvidos. Se o uso destas situações não é acompanhado por atividades de questionamento, reflexão e explicação a partir da teoria Física, as conseqüências serão mecanização e fazer sem sentido (SANTOS et al., 2000, p. 65).

Numa perspectiva mais ampla, é necessário um olhar mais crítico e cauteloso com relação ao uso dos recursos da informática em geral e, em especial, dos softwares de simulação na educação, particularmente no ensino de Física. Para tanto, entre outros esforços que visam melhorias de currículos e práticas escolares, além de investimentos tecnológicos, não se pode deixar de "investir no professor, cuja resistência e dificuldade nesta área podem ser bem maiores do que as do estudante" (MEDEIROS; MEDEIROS, 2002, p. 95).

\section{Referências}

ALAVA, S. Os paradoxos de um debate. In: ALAVA, S. (Org.). Ciberespaço e formações abertas: rumo a novas práticas educacionais? Trad. Fátima Murad. Porto Alegre: Artmed, 2002, p. 13-21.

ARAÚJO, I. S.; VEIT, E. A. Modelagem computacional no ensino de Física. Educação: Revista de Estudos da Educação, Maceió, n. 21, p. 51-70, dez. 2004.

Tecnologias computacionais no ensino de Ciências. Texto de Apoyo. $\mathrm{N}$. 24 do PIDEC, Porto Alegre: UFRGS, 2005. 75 p. 
ARAÚJO, R. S.; BARROS, S. de S.; LOPES, A. M. de A. ¿Como usar software de simulación em clases de Física? Caderno Catarinense de Ensino de Física, Florianópolis, v. 17, n. 1, p. 50-66, abr. 2000.

BIANCHETTI, L.; FERREIRA, S. de L. As tecnologias de informação e de comunicação e as possibilidades de interatividade para a educação. In: PRETTO, N. de L. (Org.). Tecnologia e novas educações. Salvador: EDUFBA, 2005. p. 151-165.

CÓRDOVA, R. S.; MAGDAlENO, J. C. M.; DONOSO, E. L.; ALlENDE, R. G. Simulación computacional de experiências de Física Moderna. Caderno Catarinense de Ensino de Física, Florianópolis, v. 9, n. 2, p. 147-151, ago. 1992.

COUTO, E.; FONSECA, D. Comunidades virtuais: herança cultural e tendência contemporânea. In: PRETTO, N. de L. (Org.). Tecnologia e novas educações. Salvador: EDUFBA, 2005, p. 53-81.

COX, K. K. Informática na Educação Escolar. Campinas: Autores Associados, 2003. 124 p.

DEMO, P. Educar pela pesquisa. 3. ed. Campinas: Autores Associados, 1998. $124 \mathrm{p}$.

FERREIRA, S. de L. A internet como espaço de construção de conhecimento. In: ALVES, L.; NOVA, C. (Orgs.). Educação e Tecnologia. Salvador: Editora da UNEB, 2003

FREIRE, P. Extensão ou comunicação? 4. ed. Trad. Rosisca Darcy de Oliveira. Rio de Janeiro: Paz e Terra, 1979. 93 p.

LÉVY, P. As tecnologias da Inteligência. Trad. Carlos Irineu da Costa. Rio de Janeiro: Ed. 34, 1993. 208 p.

MARCHAND, L. Características e Problemáticas Específicas: a Formação Universitária pela Videoconferência. In: ALAVA, S. (Org.). Ciberespaço e formações abertas: rumo a novas práticas. Trad. Fátima Murad. Porto Alegre: Artmed, 2002, p. 131-150.

MEDEIROS, A.; MEDEIROS, C. F. Possibilidades e limitações das simulações computacionais no ensino da Física. Revista Brasileira de Ensino de Física, São Paulo, v. 24, n. 2, p. 77-86, jun. 2002. 
NASCIMENTO, G. O professor e as tecnologias intelectuais: uma parceria que pode dar certo. In: ALVES, L. R. S.; SILVA, J. B. (Orgs.). Educação e Cibercultura. Salvador: EDUFBA, 2001.

PESSÔA, M. I. F. Novas tecnologias da informação e comunicação na educação: fundamentação e experiências do Pará no ensino de Ciências. In: OLIVEIRA, T. R. C. Refletindo o Ensino de Ciências no Pará. Belém: Imprensa Oficial, 2002. p. $103-128$.

PRETTO, N. de L. Uma Escola sem/com futuro. 3. ed. Campinas, SP: Papirus, $2001.246 \mathrm{p}$.

REZENDE, F. As novas tecnologias na prática pedagógica sob a perspectiva construtivista. Revista Ensaio, Belo Horizonte, v. 2, n. 1, p. 75-98, mar. 2000.

SANTOS,G.; OTERO, M. R.; FANARO, M. de los A. Como Usar Software de Simulación en Clases de Física ? Caderno Catarinense de Ensino de Física, Florianópolis, v. 17, n. 1, p. 50-66, abr. 2000.

TENÓRIO, R. M. Cérebros e Computadores: a complementaridade analógicodigital na informática e na educação. 4. ed. São Paulo: Escrituras Editora, 2003. $212 \mathrm{p}$. 